\title{
Placenta growth factor induces melanoma resistance to temozolomide through a mechanism that involves the activation of the transcription factor NF-kB
}

\author{
LAURETTA LEVATI ${ }^{1}$, FEDERICA RUFFINI ${ }^{1}$, ALESSIA MUZI ${ }^{2}$, KAZUO UMEZAWA $^{3}$, \\ GRAZIA GRAZIANI ${ }^{2}$, STEFANIA D'ATRI ${ }^{1}$ and PEDRO MIGUEL LACAL ${ }^{1}$ \\ ${ }^{1}$ Laboratory of Molecular Oncology, 'Istituto Dermopatico dell'Immacolata'-IRCCS; \\ ${ }^{2}$ Department of Neuroscience, University of Rome 'Tor Vergata', Rome, Italy; \\ ${ }^{3}$ Faculty of Science and Technology, Keio University, Yokohama, Japan
}

Received August 5, 2010; Accepted September 15, 2010

DOI: 10.3892/ijo_00000844

\begin{abstract}
Placenta growth factor (PlGF) and its receptor vascular endothelial growth factor receptor-1 (VEGFR-1) are co-expressed in a large number of human melanoma cell lines. Moreover, a correlation between in vivo PlGF production and melanoma progression has been suggested. To investigate whether PlGF might have a role in protecting melanoma cells from the cytotoxic effects of the anticancer agent temozolomide (TMZ), which is used for the treatment of this malignancy, we stably transfected a doxycyclineinducible PIGF antisense mRNA into a human melanoma cell clone that secretes VEGF-A and PIGF and expresses receptors for both growth factors. Induction of PlGF antisense mRNA in the transfected cells (13443/ASP3 subclone) halved TMZ $\mathrm{IC}_{50}$, and exogenous addition of PlGF to the culture medium $24 \mathrm{~h}$ before TMZ treatment, partially restored $\mathrm{IC}_{50}$ values to that of control cells. The increased sensitivity of 13443/ASP3 cells upon PIGF antisense mRNA expression was not due to down-regulation of $\mathrm{O}^{6}$-methylguanine-DNA methyltransferase, a DNA repair protein that represents the main mechanism of resistance to TMZ. Since the activity of the transcription factor nuclear factor- $\mathrm{\kappa B}(\mathrm{NF}-\mathrm{\kappa B})$ has been correlated to melanoma chemoresistance, we investigated whether NF- $\mathrm{KB}$ was involved in PlGF-induced melanoma cell resistance to TMZ. Induction of PIGF antisense mRNA in 13443/ASP3 cells halved the levels of active NF-kB and the specific inhibition of this transcription factor increased sensitivity of 13443/ASP3 cells to TMZ. In conclusion, our data strongly suggest that PIGF plays a role in melanoma cell
\end{abstract}

Correspondence to: Dr Pedro Miguel Lacal, Laboratory of Molecular Oncology, Istituto Dermopatico dell'Immacolata-IRCCS, Via dei Monti di Creta 104, I-00167 Rome, Italy

E-mail: p.lacal@idi.it

Key words: PlGF, temozolomide resistance, $\mathrm{NF}-\mathrm{\kappa B}$, melanoma resistance to TMZ through a pathway that involves NF-кB activation.

\section{Introduction}

The placenta growth factor (PlGF) is a member of the vascular endothelial growth factor (VEGF) family of angiogenic factors that shares with VEGF-A, the principal member of the family, and VEGF-B a transmembrane tyrosine kinase receptor (VEGFR-1). The expression of PlGF is up-regulated in several types of human cancers and is associated with a poor prognosis (1-3). PIGF is capable of transducing its own signals through the phosphorylation of tyrosine residues within VEGFR-1, which are distinct from those phosphorylated upon stimulation of the receptor by VEGF-A (4).

VEGFR-1 is expressed in endothelial cells during vessel formation and remodelling, in macrophages and in myoepithelial cells, favouring cell migration and survival $(3,5,6)$. Moreover, it is also frequently expressed in a variety of human tumours where it predicts poor prognosis and recurrence $(2,3)$. In tumour cells VEGFR-1 signalling has been shown to inhibit apoptosis and to induce chemoresistance $(2,7,8)$. Indeed, VEGFR-1 neutralization has been reported to prolong survival of tumour-bearing mice (9).

We previously demonstrated the co-expression of PlGF and VEGFR-1 in a large number of human melanoma cell lines (10) and, together with other groups, suggested that the interaction of PIGF with VEGFR-1 might modulate cellular pathways important for melanoma cell proliferation, apoptosis and invasiveness (10-14).

Malignant melanoma is a highly chemoresistant tumour. To date, no treatment options are available for melanoma patients with advanced disease that either provide sufficient response rates or significantly prolong overall survival $(15,16)$. The methylating agent dacarbazine is still regarded as the reference drug for the treatment of metastatic melanoma even though the response rate is only about $20 \%$. Temozolomide (TMZ) is an analogue of dacarbazine with similar efficacy. Differently from dacarbazine, TMZ does not require metabolic activation, is administered per os, penetrates the blood-brain barrier and is well tolerated (17). TMZ induces the formation 
of DNA methyl adducts at different base positions (18), but cytotoxicity results primarily from the formation of $\mathrm{O}^{6}$-methylguanine $\left(\mathrm{O}^{6}-\mathrm{meG}\right)$ lesions (19). In fact, tumour cells with high levels of the repair protein $\mathrm{O}^{6}$-methylguanine-DNA methyltransferase (MGMT) are resistant to TMZ (20). This enzyme is able to repair the pre-toxic DNA lesion $\mathrm{O}^{6}-\mathrm{meG}$ by transferring the methyl group from the $\mathrm{O}^{6}$ position of guanine to an internal cysteine residue (20). When the MGMT activity is low, unrepaired $\mathrm{O}^{6}-\mathrm{meG}$ mispairs with thymine during DNA replication, leading to activation of the mismatch repair system with consequent induction of apoptosis and growth arrest (21).

The transcription factor nuclear factor- $\kappa \mathrm{B}(\mathrm{NF}-\kappa \mathrm{B})$ plays a key role in the regulation of cell proliferation, inflammation, angiogenesis and suppression of apoptosis, and, when constitutively activated, may be critical in the development of drug resistance in tumour cells $(22,23)$. It consists of heteroor homodimers of five structurally related proteins: p65 (RelA), Rel B, c-Rel, p50 (NF-кB1) and p52 (NF-кB2), the most abundant form being the p50 and p65 heterodimer (24). In quiescent cells, NF- $\mathrm{KB}$ is associated in the cytosol with an inhibitory protein of the I $\mathrm{KB}$ family. Following stimulation of a variety of cell membrane receptors, IкB is phosphorylated

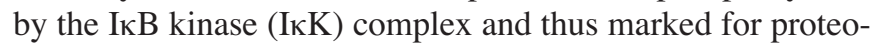
somal degradation (24). Degradation of $\mathrm{I} \kappa \mathrm{B} \alpha$ results in the release of the NF- $\mathrm{KB}$ subunits which translocate into the nucleus and bind specific DNA sequences in the promoter region of NF-кB-regulated genes, which include, among others, anti-apoptotic gene products such as Bcl-2/Bcl-xL, Mcl-1, cIAPs and survivin $(25,26)$.

In this study, we investigated whether PlGF might have a role in protecting melanoma cells from the cytotoxic effects of TMZ. To this end we utilized a melanoma model in which a PIGF antisense mRNA can be conditionally induced. Our results indicate that PIGF down-modulation significantly increases melanoma cell sensitivity to $\mathrm{TMZ}$ and that activation of the NF- $\mathrm{kB}$ signaling pathways is involved in PlGF-mediated melanoma cell resistance to TMZ.

\section{Materials and methods}

Reagents. Culture media were purchased from Sigma-Aldrich (St. Louis, MO, USA). Fatty acid-free bovine serum albumin (BSA) was from Roche Diagnostics (Mannheim, Germany). VEGF-A and PIGF homodimers and polyclonal antibodies used in ELISA assays, were from R\&D Systems (Abingdon, UK). TMZ, kindly provided by Schering-Plough Research Institute (Kenilworth, NJ, USA), was freshly prepared in complete medium immediately before use. $\mathrm{O}^{6}$-benzylguanine (BG, Sigma-Aldrich) was dissolved in ethanol $(2.4 \mathrm{mg} / \mathrm{ml})$, stored as stock solution at $-80^{\circ} \mathrm{C}$, and diluted in complete medium just before use. DHMEQ (dehydroxylmethyllepoxyquinomicin) was dissolved in dimethyl sulphoxide $(10 \mathrm{mg} / \mathrm{ml})$, stored in aliquots at $-20^{\circ} \mathrm{C}$ and diluted in complete medium just before use. The final concentration of ethanol or dimethyl sulphoxide used as solvent for BG or DHMEQ, respectively, did not affect cell growth (data not shown). MTT (3-[4,5dimethylthiazol-2-yl]-2,5-diphenyltetrazolium bromide, Sigma-Aldrich) was prepared at a concentration of $5 \mathrm{mg} / \mathrm{ml}$ in phosphate-buffered saline (PBS) and stored at $4^{\circ} \mathrm{C}$.
Melanoma cell lines. The origin of the human melanoma cell lines utilised in the study (GR-Mel, M14 and 13443-Mel) and their characterization regarding the production of VEGF and PlGF and the expression of the receptors for both growth factors, have been described elsewhere (10). The 13443-N2 cell clone was obtained from the original 13443-Mel cell line by the limiting dilution method (13).

Expression of antisense PlGF mRNA sequence in melanoma cells. Inducible expression of PIGF mRNA antisense sequence in 13443/N2 cells was achieved by using the tetracyclineregulated T-REx mammalian expression system, from Invitrogen (Groningen, The Netherlands), according to the instructions furnished by the manufacturer. The plasmid pcDNA4/ASP was a generous gift of Dr A. Fiore (Laboratory of Molecular and Cellular Biology, IDI-IRCCS, Rome, Italy). To generate this plasmid, the PIGF cDNA, obtained by RT-PCR from normal human keratinocytes, was subcloned in the antisense direction into the pcDNA-TO-myc-HisA vector (pcDNA4) provided in the T-REx system kit.

13443-N2 cells were initially transfected with the plasmid pcDNA6/TR, containing the sequence encoding a Tet repressor (provided in the T-Rex system kit), and then with the pcDNA4/ASP plasmid or with the empty vector (pcDNA4), as previously described (13). Subclones of 13443-N2 cells, containing the plasmids pcDNA6/TR and pcDNA4/ASP (ASP subclones) or the plasmids pcDNA6/TR and pcDNA4 (ASC subclones), were subsequently isolated. 13443/ASP3 and 13443/ASC1 subclones were selected for further studies. These cells were maintained in RPMI-1640 medium supplemented with $10 \%$ Tet-system approved fetal calf serum (BD Biosciences, Bedford, MA, USA), 2 mM glutamine, $200 \mu \mathrm{g} / \mathrm{ml}$ zeocin, $5 \mu \mathrm{g} / \mathrm{ml}$ blasticidin and $20 \mathrm{mM}$ HEPES (N-[2-hydroxyethyl]piperazine-N'-[2-ethanesulfonic acid]).

Expression of PIGF mRNA antisense sequence was achieved by treating semi-confluent 13443/ASP3 cell cultures with $1 \mu \mathrm{g} / \mathrm{ml}$ doxycycline (a tetracycline analogue with longer half-life) for $48 \mathrm{~h}$. For the evaluation of the amount of PlGF released in the culture supernatant by 13443/ASP3 cells after treatment with doxycycline, during the last $24 \mathrm{~h}$ of incubation, culture medium was replaced with $0.1 \% \mathrm{BSA} /$ RPMI-1640 medium containing freshly added doxycycline.

RT-PCR analysis. cDNA preparation and PCR amplification for evaluation of VEGFR-1 expression were performed as described (10), utilizing the following primers: VEGFR-1, forward primer 5'-CTCCTGAGTACTCTACTCCT-3', reverse primer 5'-GAGTACAGGACCACCGAGTT-3' (640 bp fragment); GAPDH, forward primer 5'-TCCCATCACCAT CTTCCA-3', reverse primer 5'-CATCACGCCACAGTT TCC-3' (380 bp fragment). In both cases, primer annealing was performed for $30 \mathrm{sec}$ at $58^{\circ} \mathrm{C}$.

Evaluation of VEGF and PlGF secretion. Semi-confluent melanoma cell cultures were incubated for $24 \mathrm{~h}$ in $0.1 \% \mathrm{BSA} /$ RPMI-1640 medium without serum. Culture supernatants were then collected and concentrated at least 10-fold in Centriplus concentrators (Amicon, Beverly, MA, USA). Cells were detached from the flasks with PBS/EDTA and the total cell number/culture was recorded. 
Quantification of the amount of VEGF and PIGF homodimers in the concentrated supernatants was performed as previously described (10), using Maxisorp Nunc immunoplates (Nunc, Roskilde, Denmark) coated with goat anti-VEGF or anti-PlGF IgGs at a concentration of $10 \mu \mathrm{g} / \mathrm{ml}$ in PBS. Detection of the cytokines was performed with biotinylated goat anti-VEGF or anti-PIGF IgGs and streptavidin-alkaline phosphatase conjugated $(1: 10,000)$ (Roche). Optical density at $405 \mathrm{~nm}$ was measured in a Microplate reader 3550-UV (Bio-Rad, Hercules, CA, USA). This assay allows detection of VEGF and PIGF polypeptides at concentrations equal to or $>100 \mathrm{pg} / \mathrm{ml}$. Cytokine secretion values were normalised by the total number of cells/culture.

Evaluation of cell chemosensitivity by the MTT assay. Cell proliferation was evaluated using the tetrazolium compound MTT, as previously described (27). Melanoma cells were suspended in complete medium at a concentration of $4 \times 10^{4}$ cells $/ \mathrm{ml}$, dispensed in $50 \mu \mathrm{l}$ aliquots into flat-bottom 96-well plates and allowed to adhere overnight at $37^{\circ} \mathrm{C}$. Graded amounts of TMZ or DHMEQ were then added to the wells in $50 \mu \mathrm{l}$ of complete medium and the plates were incubated at $37^{\circ} \mathrm{C}$ in a $5 \% \mathrm{CO}_{2}$ humidified atmosphere for five days. Six replica wells were used for controls and each drug concentration. Afterwards, $20 \mu \mathrm{l}$ of the MTT solution $(5 \mathrm{mg} / \mathrm{ml}$ in PBS), were added to each well, and cells were incubated at $37^{\circ} \mathrm{C}$ for $4 \mathrm{~h}$. Cells were then lysed with $100 \mu \mathrm{l}$ of a buffer containing $20 \%$ SDS and $50 \% \mathrm{~N}, \mathrm{~N}$-dimethylformamide at $\mathrm{pH}$ 4.7. After an overnight incubation, the absorbance was read at $595 \mathrm{~nm}$ using a $3550-\mathrm{UV}$ microplate reader (Bio-Rad).

TMZ was tested at concentrations ranging between 31.2 and 1,000 $\mu \mathrm{M}$ and DHMEQ at concentrations ranging between 2.5 and $10 \mu \mathrm{g} / \mathrm{ml}$. The cytotoxic effects of TMZ were evaluated also in combination with the MGMT inhibitor $\mathrm{BG}(10 \mu \mathrm{M})$ to prevent the repair of the methyl adducts at the $\mathrm{O}^{6}-\mathrm{G}$. The inhibitor was added during the overnight incubation before TMZ treatment. In the experiments aimed at testing the effect of PlGF down-regulation on cell sensitivity to TMZ, doxycycline $(1 \mu \mathrm{g} / \mathrm{ml})$ was included together with $\mathrm{BG}$ in the culture medium used to suspend the cells before dispensing them in the plates. Plates were then incubated for $48 \mathrm{~h}$ before adding TMZ.

Cell sensitivity to drug treatment was expressed in terms of $\mathrm{IC}_{50}$ (drug concentration producing $50 \%$ inhibition of cell growth, calculated on the regression line in which absorbance values at $595 \mathrm{~nm}$ were plotted against the logarithm of drug concentration).

Evaluation of MGMT activity. Cells were removed from continuous culture, washed twice with PBS and stored as pellets at $-80^{\circ} \mathrm{C}$ until used. MGMT activity in cell extracts was determined by measuring the transfer of $\left[{ }^{3} \mathrm{H}\right]$-methyl groups from a DNA substrate to the MGMT protein (28). Cell pellets $\left(3 \times 10^{6}\right.$ cells $)$ were resuspended in $1 \mathrm{ml}$ of lysis buffer (0.5\% CHAPS, $50 \mathrm{mM}$ Tris-HCl pH 8.0, 1 mM EDTA, $3 \mathrm{mM}$ dithiothreitol, $100 \mathrm{mM} \mathrm{NaCl}$, and $10 \%$ glycerol) supplemented with a cocktail of protease inhibitors (Roche Diagnostics) and incubated at $4^{\circ} \mathrm{C}$ for $30 \mathrm{~min}$. Cell lysates were then centrifuged at $18,000 \mathrm{x}$ g for $10 \mathrm{~min}$ at $4^{\circ} \mathrm{C}$. Aliquots of supernatants were then diluted in $50 \mathrm{mM}$ Tris-
$\mathrm{HCl}$ buffer, $\mathrm{pH} 8.3$, containing $1 \mathrm{mM}$ EDTA, and $3 \mathrm{mM}$ dithiothreitol, and incubated with $10 \mu \mathrm{g}$ of ${ }^{3} \mathrm{H}$-methylated DNA at $37^{\circ} \mathrm{C}$ for $1 \mathrm{~h}$. DNA was then hydrolyzed by heating samples at $75^{\circ} \mathrm{C}$ for $45 \mathrm{~min}$, in the presence of $1 \mathrm{~N}$ perchloric acid, and proteins were precipitated using $1 \mathrm{mg}$ of BSA as carrier. Pellets were washed with $1 \mathrm{~N}$ perchloric acid, resuspended in $0.01 \mathrm{~N} \mathrm{NaOH}$, and radioactivity measured in a liquid scintillation counter (Tri-Carb 1900; Packard BioScience, CT, USA), after addition of scintillation liquid (Ultima Gold; Packard Instruments Chemical Operation, Groningen, The Netherlands). Protein concentration in cell extracts was evaluated according to the method of Bradford using the Bio-Rad dye solution and BSA as standard. MGMT activity was expressed in terms of fmoles of $\left[{ }^{3} \mathrm{H}\right]$-methyl groups transferred per mg of protein in cell extract.

$N F-\kappa B$ activation assays. NF- $\kappa \mathrm{B}$ activation was analyzed in nuclear extracts, prepared using the Active Motif Nuclear Extract kit (Active Motif Europe, Rixensart, Belgium) according to the manufacturer's instructions. NF- $\mathrm{KB}$ activity in the nuclear extracts was determined using a NF-кB p65 enzyme-linked immunosorbent assay (ELISA)-based transcription factor assay kit (TransAM assay) (Active Motif Europe) or an Electrophoretic Mobility Shift Assay (EMSA).

The TransAM assay was performed according to the manufacturer's protocol using $20 \mu \mathrm{g}$ of nuclear extracts. The kit contains a 96-well plate with immobilized oligonucleotides encoding a NF- $\kappa \mathrm{B}$ consensus site (5'-GGGACTTTCC-3') to which the active form of p65 specifically binds. The NF- $\mathrm{BB}$ detecting antibody recognizes an epitope on p65 that is accessible only when this polypeptide is activated and bound to its target DNA. A horseradish peroxidase-conjugated secondary antibody provides a sensitive colorimetric readout that is quantified by a Bio-Rad Microplate Reader 680 at $450 \mathrm{~nm}$ with a reference wavelength of $655 \mathrm{~nm}$. A nuclear extract obtained from Jurkat cells stimulated with TPA and calcium ionophore provided within the Trans-AM kit, was used as internal standard in the assay. Results are expressed as arbitrary units, calculated relative to the values obtained for the Jurkat extract, according to the formula:

(sample A450/ $\mu \mathrm{g}$ protein in sample extract) x 100

Jurkat A450/ $\mu$ g protein in Jurkat extract

The EMSA was performed as previously described (29). Nuclear extracts (5 $\mu \mathrm{g}$ of protein) were incubated with ${ }^{32} \mathrm{P}$ end-labelled double-stranded NF- $\mathrm{KB}$ consensus oligonucleotide (Santa Cruz Biotechnologies, Santa Cruz, CA). Complexes were analyzed by non-denaturing 4\% PAGE and gels were subsequently dried and autoradiographed with intensifying screens.

\section{Results}

Characterization of the melanoma cell clone expressing PlGF antisense under an inducible promoter. To investigate whether PIGF might have a role in protecting melanoma cells from the cytotoxic effects of TMZ, we utilized a Tet-on gene expression system to conditionally down-modulate this cytokine in human melanoma cells. The melanoma cell 
A

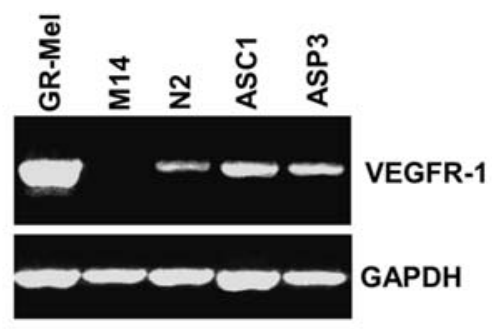

B

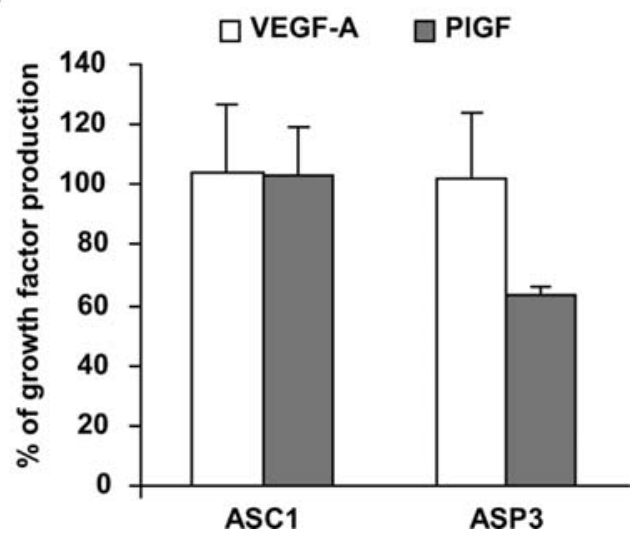

Figure 1. Characterisation of 13443/N2 subclones. (A) VEGFR-1 expression in 13443/N2 subclones. RT-PCR analysis of VEGFR-1 transcript was performed in the parental clone (N2) and the transfected subclones (ASC1 and ASP3), using the protocol and the primers indicated in Materials and methods. Melanoma cell lines GR-Mel and M14 were used as positive and negative controls, respectively. To confirm the integrity of RNA samples, the same cDNA preparations were subjected to PCR analysis of GAPDH. PCR products were separated in $0.8 \%$ agarose gels. Results are representative of one out of three different experiments. (B) Quantitative analysis of VEGF-A and PlGF released by ASC1 and ASP3 melanoma cells grown in the presence of doxycycline $(1 \mu \mathrm{g} / \mathrm{ml})$. After $24 \mathrm{~h}$ of treatment, culture medium was replaced with $0.1 \%$ BSA/RPMI-1640 medium containing freshly added doxycycline, and cell culture supernatants were collected after additional $24 \mathrm{~h}$ of culture. The amount of VEGF-A and PIGF released into the culture supernatant was evaluated by an ELISA assay. Data are expressed as percentage of growth factors detected in culture medium with respect to untreated controls. Each value represents the arithmetic mean of six independent determinations $\pm \mathrm{SD}$ of the mean. Student's t-test analysis for PIGF secretion in ASP3 cells, control versus doxycycline, $\mathrm{p}<0.001$. clone 13443-N2, that expresses VEGFR-1 and VEGFR-2 and secretes VEGF-A and PIGF (13), was initially transfected with the regulatory pcDNA6/TR vector, which encodes the tetracycline repressor, and then with the pcDNA4/ASP vector, carrying the cDNA coding for the PIGF mRNA antisense sequence under the control of a human cytomegalovirus promoter and containing two tetracycline operator sites. As a control, 13443-N2 cells were transfected with the pcDNA6/ TR plasmid and with the empty pcDNA4 vector. Two transfected subclones were selected: the 13443/ASP3 subclone (from now on referred to as ASP3 cells), containing the antisense sequence for PIGF mRNA, and the control 13443/ ASC1 subclone (from now on referred to as ASC1 cells).

The selected subclones were analyzed for the expression of VEGFR-1 by RT-PCR and the results indicated that the receptor transcript was present in both ASC1 and ASP3 cells (Fig. 1A). To specifically down-regulate PlGF expression, cells were treated with doxycycline and the amount of PIGF and of VEGF, as control, released into the culture medium was measured. After $48 \mathrm{~h}$ treatment a $40 \%$ reduction in PlGF production was observed only in ASP3 cells, while VEGF secretion was not affected by doxycycline treatment (Fig. 1B) in both subclones.

Effect of PlGF down-modulation on melanoma sensitivity to $T M Z$. ASC1 and ASP3 cells were then used to investigate whether PlGF was involved in melanoma cell resistance to the cytotoxic effects of TMZ. Down-modulation of PlGF secretion in ASP3 cells was accompanied by increased sensitivity to $\mathrm{TMZ}$, as shown by the reduction of the $\mathrm{IC}_{50}$ value for this drug from 486 to $263 \mu \mathrm{M}$ (Table I). On the other hand, in ASC1 cells doxycyclin exposure did not significantly affect $\mathrm{TMZ} \mathrm{IC}_{50}$ value (Table I). To exclude the possibility that the increased sensitivity to TMZ observed in ASP3 cells after exposure to doxycycline might be due to down-regulation of MGMT activity, we tested the level of this repair protein before and after treatment with docycycline. Both ASC1 and ASP3 subclones were found to be MGMT-proficient, being the enzyme activity higher in ASC1 cells (Table I). This finding was consistent with the higher $\mathrm{TMZ} \mathrm{IC}_{50}$ value displayed

Table I. Effect of PIGF downregulation on melanoma cell resistance to TMZ.

\begin{tabular}{l}
\cline { 2 - 4 } \\
\cline { 2 - 3 }
\end{tabular}




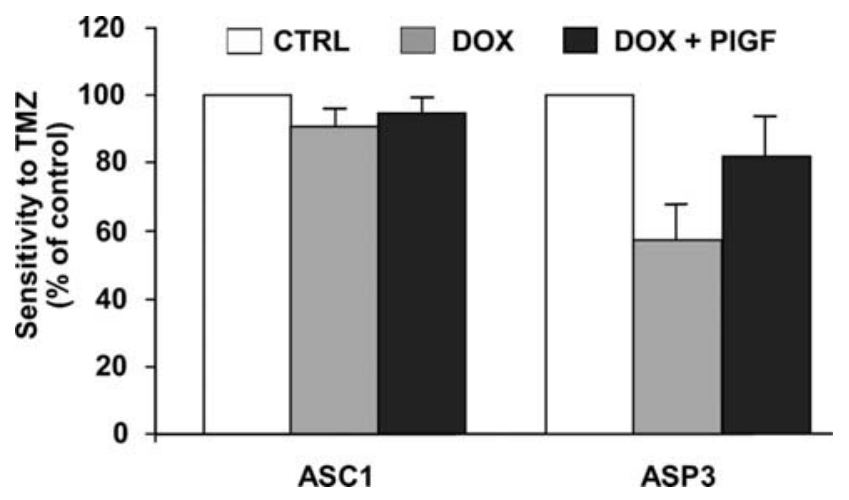

Figure 2. Exogenous PIGF counteracts the effect of doxycycline on ASP3 cell sensitivity to TMZ. $\mathrm{IC}_{50}$ values for TMZ were determined, as described in Materials and methods, in ASC1 and ASP3 cells either untreated (CTRL) or exposed to doxycycline (DOX, $1 \mu \mathrm{g} / \mathrm{ml}$ ) for $48 \mathrm{~h}$ or to doxycycline plus $50 \mathrm{ng} / \mathrm{ml} \mathrm{PlGF}$, added during the last $24 \mathrm{~h}$ of doxycycline treatment (DOX + PIGF). Data represent the sensitivity to TMZ of ASC1 and ASP3 cells relative (\%) to their respective controls not exposed to doxycycline (CTRL), calculated on the basis of the $\mathrm{IC}_{50} \mathrm{~s}$ values. Histograms represent the arithmetic mean of three independent experiments $\pm \mathrm{SD}$. Student's t-test analysis in ASP3 cells: CTRL versus DOX, $\mathrm{p}=0.008$; DOX versus DOX + PIGF, $\mathrm{p}=0.007$.

by ASC1 cells with respect to ASP3 cells. Moreover, MGMT activity was not affected by doxycycline treatment (Table I). Melanoma cells were also treated with the specific MGMT inhibitor BG before PlGF antisense induction and before exposure to TMZ. As illustrated in Table I, BG treatment significantly reduced $\mathrm{TMZ} \mathrm{IC}_{50}$ values in both $\mathrm{ASC} 1$ and $\mathrm{ASP} 3$ cells. Notably, even in the presence of BG, doxycycline treatment was able to increase TMZ sensitivity of ASP3 cells (Table I). The effect of doxycycline was partially abrogated when exogenous PlGF was added to the culture medium during the last $24 \mathrm{~h}$ of treatment with the antibiotic and before TMZ addition (Fig. 2). Therefore, PlGF appears to be able to promote protection from the cytotoxic effects of TMZ in melanoma cells.

Involvement of $N F-\kappa B$ activity in cell resistance to $T M Z$ mediated by $P l G F$. Since the activity of the transcription factor $\mathrm{NF}-\kappa \mathrm{B}$ has been correlated to melanoma chemoresistance, we investigated whether NF- $\mathrm{B}$ might be involved in PlGFinduced melanoma cell resistance to TMZ.

We initially analyzed the modulation of the level of NF- $\kappa \mathrm{B}$ activity in ASP3 and ASC1 cells upon treatment with doxycycline (Fig. 3). EMSA analysis revealed a strong down-modulation of $\mathrm{NF}-\kappa \mathrm{B}$ activity in ASP3 cells treated with the antibiotic (Fig. 3A). The reduction of NF-кB DNA binding activity was quantified using an ELISA-based transcription factor assay kit, which evidenced a $43 \%$ decrease of NF- $\mathrm{B}$ activity in ASP3 cells exposed to doxycycline with respect to untreated ASP3 cells (Fig. 3B). This effect was not observed in the control ASC1 cells (Fig. 3).

Involvement of $\mathrm{NF}-\kappa \mathrm{B}$ activity in the ability of PlGF to promote melanoma cell resistance to $\mathrm{TMZ}$ was further analyzed utilizing DHMEQ, an inhibitor of the transcription factor. This inhibitor blocks the DNA-binding activity and the nuclear translocation of $\mathrm{NF}-\kappa \mathrm{B}(30)$, and reduces cell growth of hepatoma cells in a dose-dependent manner (in a
A

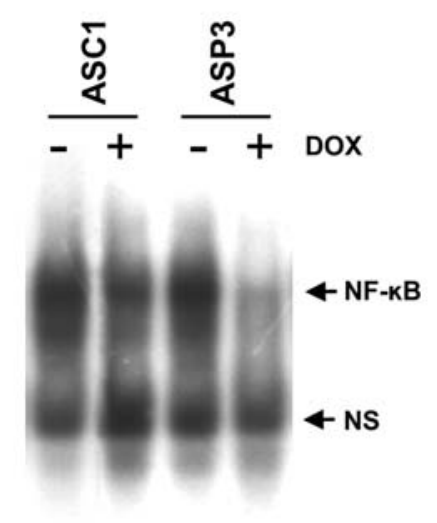

B

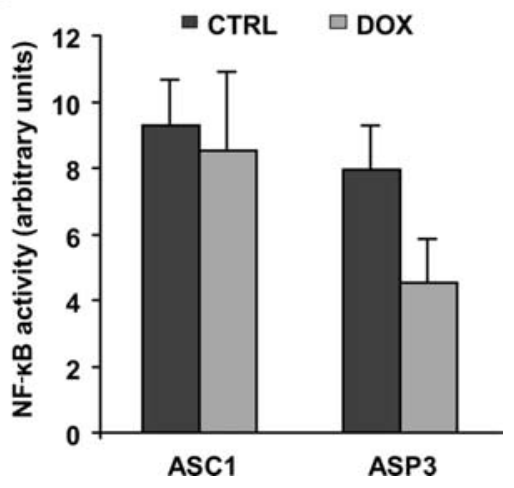

Figure 3. Effect of PlGF modulation on NF-кB activity. Nuclear extracts from ASC1 and ASP3 cells, either untreated (CTRL) or incubated for $48 \mathrm{~h}$ with $1 \mu \mathrm{g} / \mathrm{ml}$ doxycycline (DOX), were analyzed for $\mathrm{NF}-\kappa \mathrm{B}$ activity by EMSA (A) or using a quantitative Trans-AM kit (B), as described in Materials and methods. Data are representative of one out of three independent experiments with similar results (A) or represent the mean values from three independent determinations \pm SD of the mean (B). NS, non-specific. Student's t-test analysis in ASP3 cells (B), CTRL versus DOX, $\mathrm{p}=0.01$.

range from 5 to $20 \mu \mathrm{g} / \mathrm{ml}$ ) (30). Initially we evaluated the effect of DHMEQ on ASP3 cell growth with the aim of finding a concentration devoid of growth inhibitory effects but still capable of inhibiting NF- $\mathrm{BB}$ activity to be used in combination with TMZ. Cells were exposed for $3 \mathrm{~h}$ (a sufficient time for its full inhibitory activity) (31) to graded concentrations of DHMEQ and, after medium replacement and incubation for additional 5 days, cell growth was analysed by the MTT assay.

The results indicated that treatment with concentrations $>5 \mu \mathrm{g} / \mathrm{ml}$ of DHMEQ markedly impaired the growth of melanoma cells (Fig. 4A). For combination studies with TMZ, the concentration of $5 \mu \mathrm{g} / \mathrm{ml}$ DHMEQ was chosen since it almost halved NF- $\mathrm{BB}$ activity in ASP3 cells (Fig. 4B), with a minimal effect on cell growth (Fig. 4A). Preincubation with $5 \mu \mathrm{g} / \mathrm{ml}$ DHMEQ (at $37^{\circ} \mathrm{C}$ for $3 \mathrm{~h}$ ) of ASP3 cells before TMZ treatments resulted in a $\sim 50 \%$ reduction in the $\mathrm{IC}_{50}$ value of the methylating agent (Fig. 4C).

Therefore, the results indicated that the induction of PlGF antisense mRNA in ASP3 cells halved the levels of active $\mathrm{NF}-\kappa \mathrm{B}$ and that specific inhibition of this transcription factor increased sensitivity of ASP3 cells to TMZ. 
A

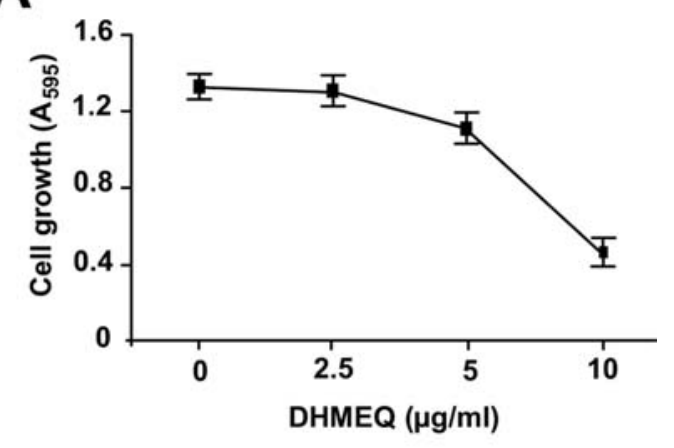

B
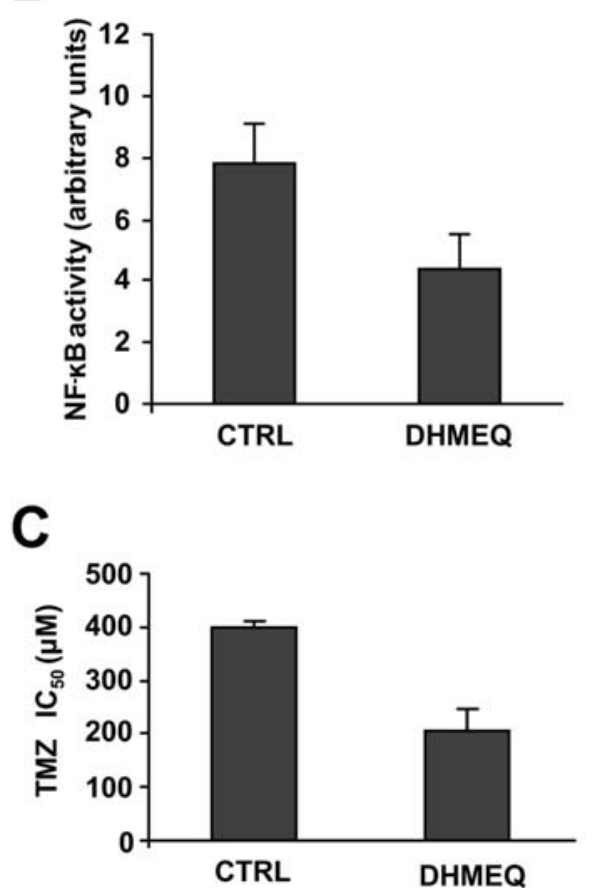

Figure 4. Effect of the NF-кB inhibitor DHMEQ on ASP3 cell sensitivity to TMZ. (A) Cells (2,000 cells/well) were allowed to adhere on 96-well plates overnight at $37^{\circ} \mathrm{C}$ and then treated for $3 \mathrm{~h}$ with DHMEQ at the indicated concentrations. Afterwards, cells were kept in culture in fresh medium without the drug for 5 additional days and cell growth was evaluated by the MTT assay. A representative experiment, out of three with similar results, is shown. (B) Nuclear extracts obtained from ASP3 cells were incubated for $3 \mathrm{~h}$ with $5 \mu \mathrm{g} / \mathrm{ml}$ DHMEQ or with the same amount of DMSO used as solvent of the inhibitor (CTRL), at $37^{\circ} \mathrm{C}$, and analyzed for NF- $\mathrm{KB}$ activity utilizing a quantitative Trans-AM kit as described in Materials and methods. Data represent the mean values of three independent determinations $\pm \mathrm{SD}$. Student's t-test analysis, CTRL versus DHMEQ, $\mathrm{p}=0.02$. (C) $\mathrm{IC}_{50}$ values for TMZ were determined, as described in Materials and methods, in ASP3 cells exposed to $5 \mu \mathrm{g} / \mathrm{ml}$ DHMEQ or to the same amount of DMSO used as solvent of the inhibitor (CRTL), for $3 \mathrm{~h}$ at $37^{\circ} \mathrm{C}$. Each value represents the arithmetic mean $\pm \mathrm{SD}$ of three independent experiments. Student's t-test analysis: CTRL versus DHMEQ, $\mathrm{p}=0.02$.

\section{Discussion}

Malignant melanoma is highly resistant to chemotherapy and once it metastasizes the prognosis is extremely poor. Only few chemotherapeutic agents have shown some efficacy against metastatic melanoma, and one of these is the methylating compound TMZ, which exerts apoptotic and cytostatic effects in melanoma cells (32). However, resistance of melanoma to TMZ is common and is frequently due to overexpression of the DNA repair protein MGMT or of antiapoptotic genes (e.g., Bcl-2). Therefore a number of strategies are under investigation in order to overcome tumour drug resistance to TMZ (reviewed in ref. 33).

Increasing data in the literature suggest that PlGF and its receptor VEGFR-1 might regulate the apoptotic pathways in tumour cells. PlGF contributes to the angiogenic and inflammatory switch in various pathologies, such as tumour growth, ischemia and arthritis (2). Moreover, clinical studies have shown that PlGF levels of expression in tumour cells correlate with poor prognosis in various tumours types $(1,2)$. In human melanoma cell lines, the expression of this cytokine and of VEGFR-1 has been described, and a correlation between PIGF expression and tumour progression has been suggested (10-14).

In this study we demonstrated for the first time that PlGF, through the activation of VEGFR-1, plays a role in melanoma resistance to TMZ, using a melanoma model in which a PIGF antisense mRNA can be conditionally induced. To this purpose, we produced a melanoma cell line, which secretes PIGF and expresses VEGFR-1, stably transfected with a doxycycline-inducible PIGF antisense mRNA (ASP3 subclone). Treatment of ASP3 cells with doxycycline caused a down-modulation of PlGF production, thus interrupting the PlGF/VEGFR-1 autocrine loop in this system. Notably, the decrease of PIGF expression resulted in increased in vitro chemosensitivity, reducing by $50 \%$ the $\mathrm{TMZ} \mathrm{IC}_{50}$.

Following the engagement of a variety of membrane receptors, the transcription factor $\mathrm{NF}-\mathrm{\kappa B}$ is translocated to the cell nucleus as a result of the activation of several signal transduction pathways. One of them is the mitogen-activated protein kinase (MAPK) pathway (34), which is also triggered by PlGF after binding to VEGFR-1 (4). NF- $\mathrm{BB}$ activation results in the induction of several antiapoptotic gene products that might be responsible for the resistance to antitumour drugs such as TMZ. Thus, to further shed light on the possible mechanism underlying the effect of PIGF on melanoma cell resistance to TMZ, activity levels of $\mathrm{NF}-\kappa \mathrm{B}$ were analysed. The results indicated that induction of PlGF antisense mRNA was associated with a significant decrease of NF- $\mathrm{B}$ activity.

Our results also demonstrate that specific inhibition of this transcription factor resulted in increased sensitivity of melanoma cells to TMZ, suggesting that the activation of the $\mathrm{NF}-\kappa \mathrm{B}$ signalling pathway might be involved in the mechanism underlying melanoma chemoresistance mediated by PIGF. To further investigate the role of NF- $\mathrm{B}$ in this process, we used the recently developed synthetic NF- $\kappa \mathrm{B}$ inhibitor DHMEQ. Differently from other NF- $\kappa$ B antagonists, DHMEQ specifically inhibits NF- $\kappa \mathrm{B}$ activity by covalent binding to the Rel family proteins p65, RelB, cRel and p50, without hampering the degradation of $\mathrm{I} \kappa \mathrm{B}(35)$. This covalent binding of DHMEQ hinders the DNA binding site of NF-kB components. The association of the NF- $\mathrm{NB}$ inhibitor with $\mathrm{TMZ}$ reduced the $\mathrm{IC}_{50}$ of the methylating agent to an extent similar to that observed upon PlGF down-modulation (36).

Recent studies performed in the murine model have shown that neutralizing antibodies against PIGF or VEGFR-1 are able to inhibit the growth and metastatic process of several 
tumours and to enhance the efficacy of chemotherapy without causing significant side-effects $(3,37)$. Our in vitro results could, at least in part, explain the mechanism underlying these in vivo observations. Overall, our data suggest that inhibition of PlGF signal transduction pathway might represent a novel therapeutic strategy to counteract the resistance of melanoma to TMZ.

\section{Acknowledgements}

The authors would like to thank Daniele Bartoloni for the artwork. This study was supported by the Italian Ministry of Health and by a FIRB grant (RBIP061.CA9).

\section{References}

1. Ho MC, Chen CN, Lee H, Hsieh FJ, Shun CT, Chang CL, et al: Placenta growth factor not vascular endothelial growth factor A or $\mathrm{C}$ can predict the early recurrence after radical resection of hepatocellular carcinoma. Cancer Lett 250: 237-249, 2007.

2. Fischer C, Mazzone M, Jonckx B and Carmeliet P: FLT1 and its ligands VEGFB and PlGF: drug targets for anti-angiogenic therapy? Nat Rev Cancer 8: 942-956, 2008.

3. Schwartz JD, Rowinsky EK, Youssoufian H, Pytowski B and Wu Y: Vascular endothelial growth factor receptor-1 in human cancer: concise review and rationale for development of IMC-18F1 (human antibody targeting vascular endothelial growth factor receptor-1). Cancer 116: 1027-1032, 2010.

4. Autiero M, Waltenberger J, Communi D, Kranz A, Moons L, Lambrechts D, et al: Role of PlGF in the intra- and intermolecular cross talk between the VEGF receptors Flt-1 and Flk-1. Nat Med 9: 936-943, 2003.

5. Adini A, Kornaga T, Firoozbakht F and Benjamin LE: Placental growth factor is a survival factor for tumor endothelial cells and macrophages. Cancer Res 62: 2749-2752, 2002.

6. Zhou Y, Bellingard V, Feng K-T, McMaster M and Fisher SJ: Human cytotrophoblasts promote endothelial survival and vascular remodeling through secretion of Ang2, PlGF, and VEGF-C. Dev Biol 263: 114-125, 2003.

7. Wu Y, Hooper AT, Zhong Z, Witte L, Bohlen P, Rafii S, et al: The vascular endothelial growth factor receptor (VEGFR-1) supports growth and survival of human breast carcinoma. Int $\mathbf{J}$ Cancer 119: 1519-1529, 2006.

8. Wu Y, Zhong Z, Huber J, Bassi R, Finnerty B, Corcoran E, et al: Anti-vascular endothelial growth factor receptor-1 antagonist antibody as a therapeutic agent for cancer. Clin Cancer Res 12: 6573-6584, 2006.

9. Fragoso R, Pereira T, Wu Y, Zhu Z, Cabecadas J and Dias S: VEGFR-1 (FLT-1) activation modulates acute lymphoblastic leukemia localization and survival within the bone marrow, determining the onset of extramedullary disease. Blood 107: 1608-1616, 2006.

10. Lacal P, Failla CM, Pagani E, Odorisio T, Schietroma C, Cianfarani, F, Falcinelli S, et al: Human melanoma cells secrete and respond to placenta growth factor and vascular endothelial growth factor. J Invest Dermatol 115: 1000-1007, 2000.

11. Graells J, Vinyals A, Figueras A, Llorens A, Moreno A, Marcoval J, et al: Overproduction of VEGF165 concomitantly expressed with its receptors promotes growth and survival of melanoma cells through MAPK and PI3K signalling. J Invest Dermatol 123: 1151-1161, 2004.

12. Graeven U, Fiedler W and Karpinski S: Melanoma-associated expression of vascular endothelial growth factor and its receptors Flt-1 and KDR. J Cancer Res Clin Oncol 125: 621-629, 1999.

13. Lacal PM, Ruffini F, Pagani E and D'Atri S: An autocrine loop directed by the vascular endothelial growth factor promotes invasiveness of human melanoma cells. Int J Oncol 27: 1625-1632, 2005.

14. Marcellini M, De Luca N, Riccioni T, Ciucci A, Orecchia A, Lacal PM, et al: Increased melanoma growth and metastasis spreading in mice overexpressing placenta growth factor. Am J Pathol 169: 643-654, 2006.

15. Li Y and McClay EF: Systemic chemotherapy for the treatment of metastatic melanoma. Semin Oncol 29: 413-426, 2002.
16. Tawbi HA and Kirkwood JM: Management of metastatic melanoma. Semin Oncol 34: 532-545, 2007.

17. Bael TE, Peterson BL and Gollob JA: Phase II trial of arsenic trioxide and ascorbic acid with temozolomide in patients with metastatic melanoma with or without central nervous system metastases. Mol Res 18: 147-151, 2008.

18. Newlands ES, Stevens MF, Wedge SR, Wheelhouse RT and Brock C: Temozolomide: a review of its discovery, chemical properties, pre-clinical development and clinical trials. Cancer Treat Rev 23: 35-61, 1997.

19. Tisdale MJ: Antitumor imidazotetrazines-XV. Role of guanine $\mathrm{O}^{6}$ alkylation in the mechanism of cytotoxicity of imidazotetrazinones. Biochem Pharmacol 36: 457-462, 1987.

20. Sharma S, Salehi F, Scheithauer BW, Rotondo F, Syro LV and Kovacs K: Role of MGMT in tumor development, progression, diagnosis, treatment and prognosis. Anticancer Res 29: 3759-3768, 2009.

21. Casorelli I, Russo MT and Bignami M: Role of mismatch repair and MGMT in response to anticancer therapies. Anticancer Agents Med Chem 8: 368-380, 2008.

22. Greten FR and Karin M: The IKK/NF-kappaB activation pathway-a target for prevention and treatment of cancer. Cancer Lett 206: 193-199, 2004.

23. Sun C, Chan F, Briassouli P and Linardopoulos S: Aurora kinase inhibition downregulates NF-kappaB and sensitises tumour cells to chemotherapeutic agents. Biochem Biophys Res Commun 352: 220-225, 2007.

24. Mohamed MR and McFadden G: NFкB inhibitors: strategies from poxviruses. Cell Cycle 8: 3125-3132, 2009.

25. Kucharczak J, Simmons MJFY and Gelinas C: To be, or not to be: $\mathrm{NF}_{-\kappa \mathrm{B}}$ is the answer-role of $\mathrm{Rel} / \mathrm{NF}-\kappa \mathrm{B}$ in the regulation of apoptosis. Oncogene 22: 8961-8982, 2003.

26. Luo JL, Kamata $\mathrm{H}$ and Karin M: IKK/NF-kappaB signaling: balancing life and death-a new approach to cancer therapy. J Clin Invest 115: 2625-2632, 2005.

27. Hansen MB, Nielsen SE and Berg K: Re-examination and further development of a precise and rapid dye method for measuring cell growth/cell kill. J Immunol Methods 119: 203-210, 1989.

28. Watson AJ and Margison GP: $\mathrm{O}^{6}$-alkylguanine-DNA alkyltransferase assay. Methods Mol Biol 152: 49-61, 2000.

29. Tentori L, Forini O, Fossile E, Muzi A, Vergati M, Portarena I, et al: N3-methyladenine induces early poly(ADP-ribosylation), reduction of nuclear factor-kappa B DNA binding ability, and nuclear up-regulation of telomerase activity. Mol Pharmacol 67: 572-581, 2005.

30. Nishimura D, Ishikawa H, Matsumoto K, Shibata H, Motoyoshi Y, Fukuta M, et al: DHMEQ, a novel NF-kappaB inhibitor, induces apoptosis and cell-cycle arrest in human hepatoma cells. Int J Oncol 29: 713-719, 2006.

31. Horie R, Watanabe M, Okamura T, Taira M, Shoda M, Motoji T, et al: DHMEQ, a new NF-kappaB inhibitor, induces apoptosis and enhances fludarabine effects on chronic lymphocytic leukemia cells. Leukemia 20: 800-806, 2006.

32. Pepponi R, Marra G, Fuggetta MP, Falcinelli S, Pagani E, Bonmassar E, et al: The effect of $\mathrm{O}^{6}$-alkylguanine-DNA alkyltransferase and mismatch repair activities on the sensitivity of human melanoma cells to temozolomide, 1,3-bis(2-chloroethyl)1nitrosourea, and cisplatin. J Pharmacol Exp Ther 304: 661-668, 2003.

33. Tentori L and Graziani G: Recent approaches to improve the antitumor efficacy of temozolomide. Curr Med Chem 16: 245-257, 2009.

34. Uffort DG, Grimm EA and Ellerhorst JA: NF-kappaB mediates mitogen-activated protein kinase pathway-dependent iNOS expression in human melanoma. J Invest Dermatol 129: 148-154, 2008.

35. Yamamoto M, Horie R, Takeiri M, Kozawa I and Umezawa K: Inactivation of NF-kappaB components by covalent binding of (-)-dehydroxymethylepoxyquinomicin to specific cysteine residues. J Med Chem 51: 5780-5788, 2008.

36. Ariga A, Namekawa J, Matsumoto N, Inoue J and Umezawa K: Inhibition of tumor necrosis factor-alpha-induced nuclear translocation and activation of NF-kappa B by dehydroxymethylepoxyquinomicin. J Biol Chem 277: 24625-24630, 2002.

37. Fischer C, Jonckx B, Mazzone M, Zacchigna S, Loges S, Pattarini L, et al: Anti-PlGF inhibits growth of $\operatorname{VEGF(R)-~}$ inhibitor-resistant tumors without affecting healthy vessels. Cell 131: 463-475, 2007. 